\title{
Sibilla Aleramo: consciência e escrita
}

\author{
Uma mulher.
}

ALERAMO, Sibilla.

Tradução de Marcella Mortara

Rio de Janeiro: Marco Zero, 1984.

Considerada pelo historiador Natalino Sapegno' uma escritora que consegue, com habilidade, unir arte e autobiografia, Sibilla Aleramo (1876-1960) é uma autora italiana ainda hoje pouco conhecida no Brasil, devido principalmente à falta de traduções de suas obras. Seu único livro que chegou até nós, objeto desta resenha, é Una donna (Uma mulher), de 1906, publicado em 1984 pela editora Marco Zero, com tradução de Marcella Mortara. Embora seja um livro do início do século XX, Una donna per-manece atual e mereceria uma nova tradução, como mostraremos a seguir.

Além de Una donna, seu livro mais famoso e mais comentado ainda hoje pela crítica, Sibilla tem uma vasta obra, composta de romances, poemas, ensaios, textos teatrais, cartas, anotações, diários, artigos jornalísticos e traduções. O material textual deixado por ela é imenso, a atestar uma produção incessante, em que a escrita é uma necessidade vital. Um dos principais temas de sua obra é exatamente o modo peculiar de sentir e de expressar da mulher, que na escrita sibilliana vincula-se a um movimento de tomada de consciência.

Não por acaso, Sibilla Aleramo tornou-se conhecida, sobretudo, por seu romance de estreia, Una donna, ${ }^{2}$ que começou a escrever em 1902, após abandonar marido e filho, e cuja repercussão foi imediata na Itália e nos países europeus nos quais foi traduzido. ${ }^{3}$ Tal repercussão fez-se sentir na televisão - nos anos 1970 Una donna é transformado em minissérie televisiva na RAI - e posteriormente no cinema - em 2002, o filme Un viaggio chiamato amore, baseado na correspondência entre Sibilla Aleramo e Dino Campana, é premiado no Festival de Veneza.
Alguns críticos, como Alfredo Gargiulo, consideram Una donna a bíblia do feminismo na Itália, afirmando que através dele Sibilla teria feito mais "em proveito do sexo do que tinham feito e andavam fazendo todas as feministas do mundo em conjunto". ${ }^{4}$ Além disso, podemos dizer que Sibilla antecipa um pensamento relativo à mudança de paradigma que irá transformar a sociedade italiana na segunda metade do século $X X$.

Una donna é dividido em três partes, com 22 capítulos breves, e narra as vicissitudes da protagonista em ordem cronológica, da infância até $\mathrm{o}$ momento em que redige o livro. Na primeira parte, iniciada com uma infância feliz e livre, a protagonista narra $\circ$ abalar desse mundo "perfeito", a começar pela quebra da imagem que tinha do pai, pela revelação de uma mãe depressiva e suicida, pela experiência da violência sexual, que dá origem ao casamento arranjado para encobrir a situação, pela relação infeliz, pelo nascimento do filho e pela sua própria tentativa de suicídio. A segunda parte narra a abertura da protagonista para 0 mundo: o encantamento por leituras (Nietzsche, Ibsen, Whitman), o início da escrita, os primeiros contatos com as lutas sociais, com o mundo político e cultural das mulheres. A terceira parte, por sua vez, concretiza o processo de "renascimento" da protagonista iniciado na segunda parte, que, ao fim de um percurso de tomada de consciência da própria vida, transforma a sua história num "libro-verità".

Una donna, de fato, é o relato do despertar da consciência de uma mulher através da expressão literária. É fundamental na compreensão das bases da poética da autora e marco do nascimento da identidade literária de Sibilla Aleramo, pseudônimo de Rina Faccio. Há no livro, segundo Marina Zancan, um predomínio absoluto do 'eu narrante': os personagens não têm nome, só são inseridos na trama da narrativa à medida que são projetados pela consciência da protagonista. ${ }^{5}$ Essa narração, em tom confessional, transforma a experiência própria em 'obra de verdade', revelando aquele que será 
um lema constante, quase obsessivo, de toda a produção artístico-existencial sibilliana: sua exigência absoluta, sua total e irredutível fidelidade à verdade, que será sempre a verdade da escritora, consequência direta do conceito de obra literária, e de literatura como um todo, de Aleramo. ${ }^{6}$

A protagonista de Una donna narra a necessidade que sentia de escrever o livro que transformaria a própria história numa história exemplar de mulher:

Un libro, il libro [...] Ah, non vagheggiavo di scriverlo, no! Ma mi struggevo, certe volte, contemplando nel mio spirito la visione di quel libro che sentivo necessario, di un libro d'amore e di dolore, che fosse straziante e insieme fecondo, inesorabile e pietoso, che mostrasse al mondo intero l'anima femminile moderna, per la prima volta, e per la prima volta facesse palpitare di rimorso e di desiderio l'anima dell'uomo, del triste fratello [...] Un libro che recasse tradotte tutte le idee che si agitavano in me caoticamente da due anni, e portasse l'impronta della passione. ${ }^{7}$

Para Maria Antonietta Macchiocchi, em seu prefácio político de 1973, reproduzido na edição brasileira, Uma mulher é um livro que dá "um impulso à batalha da emancipação feminina como batalha revolucionária". Ela ainda afirma que o livro "não pertence ao passado, mas ao presente e ainda quem sabe até onde ao futuro" (p. 5). Embora essas considerações de Macchiocchi sejam feitas a partir de sua observação em relação à mulher italiana dos anos 1970, podemos dizer que Una donna é universal, pois discute a situação da emancipação da mulher dominada por aquilo que Macchiocchi chama de "moralismo pequeno-burguês e burguês, onde a moral oficial [...] está, ainda hoje, na fórmula ambígua de mulher + família + educação dos filhos + paridade no trabalho e na família" (p. 5).

Sibilla desperta como escritora justamente quando os movimentos de emancipação da mulher começam a ganhar força no país ${ }^{8}$ e se distingue por não ser apenas mais uma autora, uma artista como Matilde Serao, Grazia Deledda, Vittoria Aganoor, mas também uma "reivindicadora da paridade feminina, uma rebelde". 9

Certamente Casa de bonecas, de lbsen, ${ }^{10}$ impulsiona a escrita de Una donna. A Nora de lbsen é uma mulher supostamente feliz, que se anula e mente para manter a segurança do status quo conquistado na vida familiar. Mas alguns acontecimentos fazem com que ela se enxergue diferente, e Nora então resolve desmascarar o escondido e seguir sua estrada, abandonando tudo, como na história de Sibilla. Ambas as protagonistas rompem a alienação familiar nesse movimento de tomada de consciência e busca da verdade, mas em Una donna se destaca a relação entre consciência e escrita - marca registrada de Sibilla, como já observado.

Outra aproximação possível em tempos distantes é a de Una donna, de Sibilla Aleramo, com os escritos de outra italiana, Natalia Ginzburg (1916-1991), principalmente os da produção teatral dos anos 60 do século passado. Natalia utiliza-se de personagens femininas submetidas à autoridade de seus maridos ou pais. De modo geral, são mulheres que veem os seus casamentos se arruinarem, ou personagens que não realizam os seus desejos de amor e de relações sentimentais. A relação entre essas personagens está ligada ao acaso e à chiacchiera, como as únicas razões de vidas cinzentas, alienantes, repetitivas, sem esperança. Além disso, Ginzburg, em suas peças, mostra a falência da família e a crise existencial da personagem feminina, tal como Sibilla.

Cecilia Casini fala da produção literária sibilliana como um "percurso de formação em ato", aproximando-o da experiência inglesa de "Bildungsroman" (Jane Austen, George Eliot, irmãs Brontë). Nesse sentido, ela diz que Sibilla "representa bem - principalmente em Una donna e II passaggio - uma modalidade de constituição da cultura humana, isto é, uma 'forma simbólica' da modernidade, permanecendo ainda hoje central na reflexão sobre a identidade literária feminina". ${ }^{11}$

Sibilla Aleramo foi, de fato, uma das primeiras escritoras italianas a apresentar uma reflexão sobre a autonomia da expressão da mulher na escrita. A modernidade das ideias de Sibilla é, segundo Casini, ${ }^{12}$ um dos motivos principais pelos quais sua obra, ainda hoje, comove e atrai. Apesar de ser uma autora "em parte superada, irremediavelmente 'donna dell'Ottocento'", Aleramo difunde em seus escritos intuições sobre a condição da mulher e trata de temas universais como o amor, a escrita, a vida, que revelam um olhar moderno de uma mulher à frente de seu tempo.

Segundo Marina Zancan, Una donna é um livro difícil, que pode ser lido pelo viés das teorias feministas, psicanalíticas etc., cujo tom confessional e lírico do relato não facilita a versão do texto para outras línguas. Mas, se entendemos - traduzir mantendo a sua ordem, sem 
acréscimo nem omissão, sem cortes, desenvolvimento, alteração das personagens, a tradução brasileira peca por algumas omissões e cortes, talvez por falta de uma revisão mais acurada, embora isso não comprometa a compreensão do texto original.

Pela atualidade do livro, pelo fato de a autora ser desconhecida no Brasil, fruto da quase ausência de traduções de suas obras em português, e porque momentos históricos diferentes requerem uma nova tradução, seria interessante retraduzir Una donna, que não pode ser considerado um livro datado. Aliás, a modernidade de Sibilla Aleramo, e, particularmente, de Una donna, reside em abordar questões que estão além da batalha pelos direitos igualitários de sua época, antecipando um pensamento sobre a singularidade da subjetividade feminina proposto pelas feministas dos anos 1970.

\section{Notas}

' Natalino SAPEGNO, 1975.

${ }^{2}$ Embora a menção a Sibilla Aleramo nas histórias literárias seja bastante breve, na história literária organizada e publicada por Asor Rosa em 1995, há uma seção dedicada inteiramente a analisar os diferentes aspectos de Una donna, através do minucioso estudo de Marina Zancan.

${ }^{3}$ Entre 1907 e 1909 o romance foi traduzido para seis línguas: francês, inglês, espanhol, alemão, russo e sueco. De acordo com as fontes consultadas (Adriana Aikawa da Silveira ANDRADE, 2009), há publicações de traduções das obras de Aleramo em francês, inglês, alemão, espanhol, grego, holandês, sueco, húngaro, dinamarquês, russo, croata, eslovaco, catalão e português. Una donna é a obra mais traduzida de Sibilla Aleramo: à parte as traduções europeias feitas nos anos imediatamente sucessivos à sua primeira edição na ltália, o livro ganhará traduções que acompanham $\circ$ movimento de 'redescoberta' da autora nos anos 1970 e 1980 para o holandês, grego, esloveno, português, dinamarquês, além de novas traduções para o inglês, francês, espanhol e alemão. Vale lembrar que a França foi o país que traduziu praticamente toda a obra de Sibilla.

${ }^{4}$ GARGIULO apud Emilio CECCHI, 1984, p. 194.

${ }^{5}$ Marina ZANCAN, 2000.

${ }^{6}$ Maria Cecilia CASINI, 2005, p. 24.

${ }^{7}$ Sibilla ALERAMO, 2005, p. 92.

${ }^{8}$ Vale lembrar que, embora Sibilla Aleramo já se torne conhecida ao publicar Una donna, há um movimento de redescoberta da autora quando a luta feminista está em fase mais avançada, ou seja, reivindicando o divórcio e os direitos sobre o próprio corpo. É um período de grandes mudanças na ltália: o divórcio foi legalizado no país em 1970; os métodos contraceptivos, em 1971; e em 1978, um referendum legalizou o aborto. Aqui a raiz da luta não é exatamente a emancipação feminina, mas o reconhecimento da especificidade da identidade feminina, a afirmação dos direitos singulares da mulher. Nos tempos de Una donna a luta era por direitos mais básicos, como o direito ao voto (conquistado só em 1946), à instrução (acessível a poucas) e contra a exploração da mão de obra feminina nas fábricas (no processo de modernização da sociedade italiana as mulheres inserem-se no mercado de trabalho, mas ocupam cargos desqualificados ou ganham salários inferiores, como as crianças. Ainda não estavam organizadas em sindicatos, como os homens, por exemplo).

${ }^{9} \mathrm{CECCHI}, 1984$, p. 195.

10 Sibilla lê Casa de bonecas nos anos anteriores à publicação de seu romance e assiste à encenação dessa peça anos depois, nos tempos de seu ensaio "Apologia dello Spirito Femminile", de 1911.

1 CASINI, 2005, p. 17

${ }^{12}$ CASINI, 2005, p. 203.

\section{Referências bibliográficas}

ALERAMO, Sibilla. Una donna. Milão: Feltrinelli, 2005.

ANDRADE, Adriana Aikawa da Silveira. Ensaios de Sibilla Aleramo: uma tradução comentada. 2009. Dissertação (Mestrado em Estudos da Tradução) - Programa de PósGraduação em Estudos da Tradução, Universidade Federal de Santa Catarina, Florianópolis, 2009.

CASINI, Maria Cecilia. Sibilla Aleramo: uma mulher escrevendo na aurora do século $X X$. 2005. Tese (Doutorado) - Faculdade de Filosofia, Letras e Ciências Humanas, Universidade de São Paulo, 2005.

CECCHI, Emilio. "Posfácio". In: ALERAMO, Sibilla. Uma mulher. Tradução de Marcella Mortara. Rio de Janeiro: Marco Zero, 1984. p. 194.

SAPEGNO, Natalino. Disegno storico della letteratura italiana. Firenze: La Nuova Italia, 1975.

ZANCAN, Marina. "Una donna di Sibilla Aleramo". In: ASOR ROSA, Alberto (Org.). Letteratura italiana. Le Opere. II Novecento. Turim: Einaudi, 2000.

Andréia Guerini e Adriana Aikawa da Silveira Andrade

Universidade Federal de Santa Catarina 